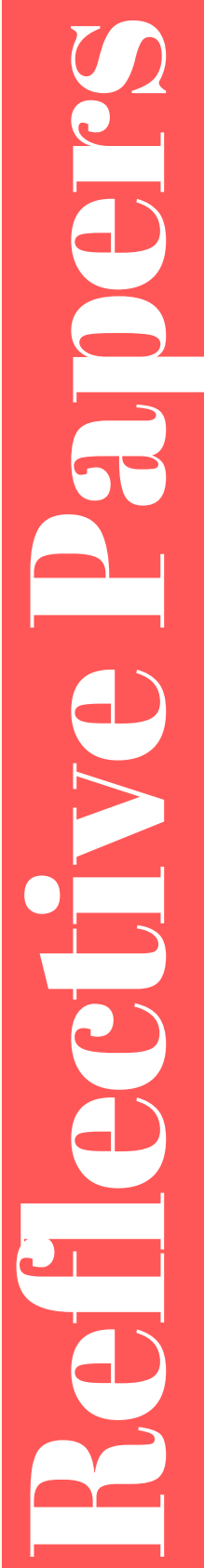




\title{
A General Review of the Role of Technology in the English \\ Language Learning Processes
}

Una revisión general del rol de la tecnología en los procesos del

aprendizaje de inglés

\author{
Arnold Yesid Rojas \\ Universidad Pedagógica y Tecnológica de Colombia \\ arnold.rojas@uptc.edu.co \\ Luis Alejandro Novoa \\ Universidad Pedagógica y Tecnológica de Colombia \\ luis.novoa@uptc.edu.co \\ Santiago Andrés Sandoval \\ Universidad Pedagógica y Tecnológica de Colombia \\ santiagoasandoval@gmail.com
}

Received: August 21, 2019

Accepted: October 23, 2019

How to cite this article (APA, 6th ed.):

Rojas, A. Y., Novoa, L. A., \& Sandoval, S. A. (2019). A general review of the role of technology in the English language learning processes. ENLETAWA Journal, 12(2), 78-96.

\begin{abstract}
This article aimed at presenting general trends regarding the role of technology in the English language learning process. The benefits of using technology in the process of learning English, as well as the importance of using technology as a method to teach a foreign language, will be discussed. This study discusses the use of technology as a way to promote teaching English as a foreign language, as well as how it can transform the teaching and learning process.
\end{abstract}

Key words: English language learning, ICT, technological devices, technology. 


\section{Resumen}

Este artículo presenta algunas tendencias asociadas al papel de la tecnología en los procesos de aprendizaje del idioma inglés. Además, se mencionan los procesos y beneficios que se pueden obtener utilizando la tecnología, así como la importancia del aprendizaje del idioma inglés mediado por la misma como una nueva metodología para la enseñanza del idioma extranjero. Del mismo modo, el documento aborda la trascendencia de la tecnología como un promotor para la enseñanza del inglés, y como un fenómeno que transforma los procesos de enseñanza y aprendizaje.

Palabras clave: aprendizaje de inglés, dispositivos tecnológicos, tecnología, TIC. 


\section{Introduction}

It is not a secret that digital environments, mobile devices, and technology have changed and reshaped education. Technology has impacted almost every aspect of life today, and education is no exception. This increase in technology within education can be unsympathetic to those without the means or ability to access the tools required in the language learning process. Kàrpàti (2011) stated that "students can access information more easily, as a growing amount of data is available in digital repositories that are much easier to access than traditional, paper-based resources for learning" (p.v4). Although some people consider the use of technological resources suitable during the learning process, others, as Bedoya (2013) suggested, think just the opposite.

The impact of technology in the educational field has grown exponentially, and this paper aims to identify some of the trends in the role of technology in the English language learning process. Over the last decade, the use of technology in the English language learning process has radically changed the idea of how language is learned. Technology has not only been used to promote language learning, but it has also transformed the process of teaching and learning a language. Moreover, technology has profoundly changed education, and we attempt to explain the ways it has changed teaching and learning, as well as its implications.

The role of technology in the classroom can be seen from both the students' and teachers' perspectives. During the educational process, and especially while studying English as a foreign language, we have seen how the use of technology has created a supplement to the traditional methodology of teaching and learning a foreign language. In fact, technology has helped improve the English language learning and teaching process due to creating a reciprocal relationship while allowing teachers to enhance their pedagogical practices. Bolivar (2013) 
mentioned that "We could find as the use of the technological devices offer new perspectives for language learning" (p. 128).

When a teacher utilizes technology as a teaching methodology, he or she can find new possibilities to teach. Meanwhile, students are encouraged to learn autonomously. However, not all teachers make use of technological devices adequately. In some case, teachers may underutilize the technology they have at their disposal. Nevertheless, the trend to use technology in the classroom has been on the rise. As a result, new ways to use technology have been showing up in education. Furthermore, many school and educational institutions have tried to implement technology in their curriculums. This has resulted in new processes to help students and teachers change their perception about what the classroom is like, what should be taught, and how content should be presented.
According to Blurton (2002, as cited in Bolivar, 2013), ICT (Information and Communication Technologies) is made up of a diverse set of technological tools and resources used to communicate, create, and manage information. Our world is experiencing changes which are important in our daily lives. Teachers have had to experiment with how these changes have transformed education and the language learning process in their classrooms. Most students and teachers have moved away from the traditional teaching method, and they have had to adapt technology in their class in one way or another.

Consequently, Tondeur, Hermans, Van Braak, and Vacke (2008) have found that "traditional teaching profiles are associated with low-computers use, whereas constructivist teaching profiles, in which students take an active role in learning, are associated with higher computer use" (p. 96). To this, we add that technology does not equate to using computers. Rather, technology in the 
classroom is a result of how teachers and students use technological resources. Meanwhile, students, as is the case with most of our peers in the undergraduate program, may prefer to look at images or watch a movie rather than a book. In this case, technology could be useful in helping promote language learning in meaningful ways. In the following paragraphs, we discuss insights on various methodologies related to technology and the classroom.

\section{English Language Learning Mediated by}

\section{Technology}

Technology has become an essential tool along with its application in the classroom to teach English as a foreign language. It has transformed teachers' perceptions and students' interests in what learning a language means. The introduction of technology has allowed people to have easier access to information and knowledge. Houcine (2011) stated that "technological devices give teachers the possibility to adapt the teaching materials easily according to the circumstances, learner's needs and response; it offers access to authentic materials" (p. 129). As teachers, we must identify each students' unique abilities, so that we can develop strategies that help increase each students' interest. One way we can tackle individual students' needs is through technology.

Technology is a multifunctional tool that can be used to transform the classroom while motivating students to learn. As stated by Bolivar (2013), "technological devices are a group of elements that allow the interaction of teachers and learners to improve foreign language proficiency" ( $p$. 129). In addition, technology can help improve students' skills and proficiency.

In the Colombian context, it is important to analyze the factors that impact students in the classroom. As stated by Aguirre and Ramos (2014), "Colombian schools nowadays demand teachers who adapt their methodologies to cope with diverse students' needs in a classroom" ( $p$. 138). It is necessary to look for new 
methodologies that improve students' understanding and help guide them through the curriculum, which should be adapted to the students' needs. As mentioned before, technology could encourage autonomous learning, which has been connected to proficiency through different technological devices. Despite the difficult circumstances in Colombia, most students have access to the technological tools and strategies necessary to learn English.

Students' performances in learning will be of utmost importance for future teachers. Furthermore, teachers will want to respond to their students' needs through critical teaching. In addition, teachers should continually find ways to improve their learning in order to improve their teaching. This creates a mixture of traditional and futuristic teaching styles that can create a new methodology that improves the learning processes for students and teachers alike.

Kumaravadivelu (2001) has described new pedagogical styles based on particularity, practicality, and possibility. He suggested a more meaningful teaching approach for students and teachers that manages individualities while identifying their needs. Giraldo (2013) mentioned that, Theory and practice in professional development programs have a reciprocal relationship, which can have a positive impact on teachers and their practice. These programs should include opportunities for teachers to make sense of theory and to criticize and use it meaningfully for classroom contexts. (p.75)

In the case of pre-service teachers, it is crucial for them to look for alternatives to teaching their future students. Technology as a methodology can provide pre-service teachers with new ways of connecting knowledge and experiences with different cultures.

It is important to highlight the fundamental role that teachers play in the development of a new vision of learning 
and teaching. New teachers must have a solid pedagogical approach that combines technology and the motivation that revolves around technology. A teacher's goal should always be to outline strategies that help students gain knowledge and understanding.

Over the past decades, technology has become a tool which has changed the educational landscape. Technology is rooted in our daily lives. As a result, it can be found almost everywhere. The use of technological devices as educational resources has become another extension of technology and even part of our culture. Consequently, teachers can choose to take advantage of technology and use it to complement their teaching practices. From the biggest to the smallest institutions, the use of technology in the learning process has been studied and adapted for its best implementation. Students and teachers have been able to complement their educational process using new methodologies within the language learning process through the implementation of different technological advances.

Salinas (2011) stated that "currently there is an increasing interest in using the virtual modality to teach and learn foreign and second language" (p. 135). Language teaching is very different than it used to be when traditional approaches were the norm inside the classroom. The author also stated how ICTs in Colombia have challenged teachers, students, and the academic community in order to improve and better implement their pedagogical practices. Teaching and learning methodologies have been reshaped primarily because students' interests have changed. As a result, teachers' roles have also changed to keep up with new ideologies. The goal of technology has extended to cover almost every socio-cultural factor in society, and education has taken advantage of this tool in order to develop better teaching and learning practices.

As technology provides the possibility to rebuild and reshape 
educational trends, teachers also have had to reconstruct their own teaching perspectives. Bedoya (2014) mentioned that "some teachers that work in virtual environments need to put aside prejudices about virtual education and open their minds to thinking that English can be learned in the virtual modality" (p. 95). Bedoya suggested that teachers should go beyond the traditional setting and method in order to teach English language lessons.

However, face-to-face learning has a significant impact on students and teachers that could be difficult to recreate with technology. Bedoya (2014) stated that there are perks with technological resources, but most of the participants in her study preferred to be immersed in a personal and interpersonal approach, where they could receive clear instructions and the interaction was more suitable to learn.

Bedoya (2014) reaffirmed her hypothesis based on her participants' voices mentioning that "they still believe that the teacher is the main character of the scene and that learning depends a lot in him/her" (p. 95). Whether the classroom is virtual or face-to-face, students are not always keen on being active agents in their learning processes. Instead, students may feel more comfortable absorbing the target language through instruction. However, we believe that students should notice that things have changed, and that almost all pedagogical processes will depend on them. Additionally, students should realize the importance of certain learning resources over others. To this, we add that the teacher's role is crucial, but it is his or her ability to connect with students and build meaningful learning environments that will matter most.

In addition to teachers and students' perceptions, new language material must also account for the socio-cultural aspects that will allow the class to function. Pinzón and Guerrero (2018) suggested important aspects to consider when planning a lesson. For example, when a new idea or project is introduced, teachers, students, and directors 
can determine whether or not to adopt it. In order to adopt the material, they must take into account five different factors:

1. Relative advantage (How is it better than previous material?)

2. Compatibility (How coherent it is with values and experiences?)

3. Complexity (How people understand it)

4. Trialability (What is the possibility of trying it out in a short time span?)

5. Observability (How are the results are visible?). (p. 73)

If the innovative material, idea, or methodology is suitable for the context and student body, the teaching methodologies will also change when a different resource is applied. The previous will determine whether technological devices are used inside of the classroom, as well as if they are relevant to teaching English as a foreign language.

Furthermore, institutions must also make decisions based on the five aspects as to implement technology, and whether it will be sufficient to language learning. Because of this, we see that technology represents a big challenge for most traditional teachers and institutions. Although this is changing every day, traditional methodologies are a hurdle that inhibit the implementation of technology. In some contexts, technology will impact the population. Nevertheless, its efficiency will be a result of the knowledge and implementation of these resources, which may not always be the most advantageous. Despite the resistance to use technology in many contexts, it is still a pedagogical resource that can be used to innovate the teaching and learning process. According to Cariaga (2016), the technological phenomenon has permeated almost every corner around the world, and those digital tools are linked to the ease of the learning process for certain topics. As a result, it is vital for educational institutions to examine their perspectives, practices, and theories related to the traditional 
methodology of teaching in light of new methodologies in classroom development. Cariaga added that "it is crucial for individuals of the 21 st century to be capable of using new communication tools" (p. 89).

Cariaga (2016) stated that technology offers a variety of possibilities to teach and learn knowledge, including English as a Foreign language. Meaningful learning must include the combination of audio-visual, linguistic, gestural, and spatial modalities in order to be successful. The importance of integrating digital material into the learning process has a specific role and has the power to transform students' interests and their perceptions about the class. Technology can play a crucial role in students' ability to have a meaningful engagement with a teacher. When a teacher plans their class around implementing technology to teach a language, the atmosphere in the classroom changes because students can interact with the digital texts, sounds, and images that technology offers.
The use of technology inside a class also allows students and teachers to reshape their way of facing the language learning process. According to Pinzón and Guerrero (2018), the implementation of different contextualized materials to develop the class using technology helps participants change their attitudes while learning the language. Other authors have explained the relevance of technology as a teaching methodology. Castellanos (2009), Clavijo, Hine, and Quintero (2008), Cuesta (2010), Rogers (2008), and Rojas (2007) suggested that technology can be used to promote and foster English language learning through the use of appropriate tools as long as it maintains the needs of the institution and the students.

$$
\text { Moreover, Salinas }
$$

mentioned that the best way to implement technology as a pedagogical resource is as follows,

The decisions about how, when, where, and why to use this tool must be made by teachers, students, and 
institutions depending on their needs. Despite the multiple advantages ICTs offer, we also need to be aware of their possible limitations and the best ways to optimize this resource. (p. 31)

As mentioned before, technology has changed the roles of teachers and the students inside the classroom. Technology has shifted this focus to one where students and their self-learning process becomes a collaborative effort. In this case, each participant creates new knowledge to reach a common goal of learning the English language. Various educational institutions have had a duty to redesign their teaching methodologies and learning spaces in order for students to have a more meaningful learning process when technology has been implemented.
Technology as a Promoter to Teach the English Language

Although some English language teachers may lack experience at the beginning of their careers, they do not lack a sense of ingenuity and strive to find new ways to educate their students. One of these new methods is the use and implementation of technology. The abundance of technology allows teachers to think more openly about the uses of these devices (cellphones, smart TVs, etc) inside the classroom.

It is necessary to analyze the extent to which teachers impact their students in regard to new ideas for teaching a language. This also opens the door to explore why some English language teachers firmly believe that they are protecting their students from new concepts including the implementation of technology. As Reinders (2018) pointed out, "in most cases teachers have genuine and reasonable concerns about protecting their own professional practice as well as their learners" (p. 70). 
Nevertheless, the students' needs should be considered over teacher's perspectives. According to Andrade (2014),

Technology is a resource to be used by the students as they solve problems, seek information and understanding, and find ways to apply what they have learned in ways that are both personally and socially meaningful. In addition, I realized that technology should not change teaching methods, but its inclusion should enhance and improve students' learning. (p.44)

It is vital that English language teachers look at the ways in which technology can help with the needs of their students. Teachers can then utilize their professional experience to enhance the classroom by implementing technological aids.

\section{The Transformation of the Teaching and} Learning Processes

Technology has transformed science, medicine, economics, sociology, and virtually every field in the world. For this reason, the teaching process of preservice teachers must change especially for English language teachers. Without technology, we are limiting ourselves to the world. As Muñoz (2016) stated "la interacción se convierte en uno de los cambios de la educación digital que posibilita el encuentro con otros sujetos en el mismo lugar, momento y situación, aspectos que componen la presencia" (p. 211). Technology works as a gateway that connects a variety of external components related to the learning process to promote students' ability to express their creativity. This educational transformation is what will generate a unique combination of processes that meet the objectives of teachers and students required to face a future full of possibilities. 
Future teachers and their pedagogical practices will play an enormous role on the motivation and success that students achieve in learning. It is important to think about each situation, aspect, and circumstance, as well as find out what motivates students to learn for themselves. Students will see the need to learn, without the pressure of a grade or criticism. They should feel a desire to learn for themselves through the proper use of technology. Cubides and Rodriguez (2013) stated that "because of globalization, expansion of languages, and the movement of people from country to country, foreign language learning has changed from different perspectives" (p. 24). These perspectives are related to the skills that learners must acquire which include speaking, reading, writing, and listening. These skills are intertwined with new ways of learning that are provided by technology and characteristic of globalization. The movement of people to other countries and their capacity to interact with other cultures using technology increases the benefit of learning new languages.

The transformation of students and teachers should be mutual. Students can also provide ways to communicate their circumstances related to their learning and propose alternatives. Learning alternatives may include activities that are commonly used by young people today, including video games. La Verde (2013) mentioned that "videogames can result in a very useful way for teaching English because of their reading and listening contents" (p 131). Students could also create a learning environment, which consists of learning from each other while the teacher acts as the mediator of knowledge.

Teachers and students' motivations and experiences can influence learning and knowledge. The motivation and knowledge gained will generate a new vision of the future. Many people are motivated by the desire to be better or improve certain aspects of their lives. It is important to emphasize that teachers play a key role as 
motivators in the learning process. A student's desire to improve those aspects of their lives is reliant on having the support and motivation of a teacher. As argued by Morales (2016), “teaching education programs need to reinforce spaces in which student-teachers can share their experiences lived at schools, their feelings in relation to their performance, and their concerns about classroom management, among others" ( $p$. 56). Students and teachers need to create dialogue and share experiences within each learning environment in order to build a successful relationship.

Since learning and teaching are a part our lives, we must also understand that we learn in different circumstances. Just because we have roles as teachers or students does not mean that learning cannot be carried out reciprocally. It is important to have an open mind to listen to positive experiences related to learning and teaching. It is also essential to analyze the positive and negative aspects of each experience to fully take advantage of the benefits technology has in the English learning process. As teachers, we must find the means to motivate our students and help them access vital information using technology so they can reach their dreams.

\section{Implications}

In Colombia, technology is being implemented in almost every educational institution.

It is also becoming a part of the culture since it facilitates the communication and interaction with the world. Most English language teachers, pre-service language teachers, and English language students in Colombia perceive technology as an important tool that is gaining relevance in their respective fields of study.

As teachers begin to look for alternatives in the process of teaching and learning a language, the idea of implementing technology within the classroom is seen as a progressive one. Andrade (2014) stated that "technology not only increases motivation, independence 
and self-confidence in English Language

Learners, but also improves their language

skills” (p. 43).

Technology has been seen as a way

to support, change, and transform our daily

lives and, as a result, has impacted almost

every field in our society. This impact has

also been felt in the educational field where

both teachers and students' perceptions

have been affected. As is the case with all

new tools, it has its pros and cons.

Therefore, teachers, educators, pre-service

teachers, and students must reassess their

role in society because education has also

been renovated. There is a need to analyze

how useful technology may be in learning a

language and what impact it will have on daily life.

Technology is found everywhere, and both teachers and students use it for different aspects of life. Sometimes this can be in the form of enjoying time or learning a new and meaningful skill. If the use of technology for learning English is used properly, students and teachers will receive immeasurable benefits. For this reason, it is important that future teachers use and develop these tools for future implementation.

It is also worth mentioning that technology tries to promote knowledge. It offers people the possibility to learn in a different environment at their own pace. Although technology has its own boundaries, it is a useful tool which must be explored to the best of our ability. This ability to continue learning new boundaries also gives everyone the opportunity to learn other languages and cultures. Learning a language using technology is a supportive method of learning knowledge placed in our hands. Teaching practices supported by technology can change the whole atmosphere of the class and promote selfmotivation. Teachers need to motivate students and connect what they are learning to possible life experiences. Technology provides the chance to empower students and teachers to learn and encourage selfmotivation. 


\section{About the Authors:}

Arnold Yesid Rojas Rincon is a tenth semester student from the Modern Language undergraduate program at UPTC. He is part of the research group TONGUE that belongs to the Modern Languages School, and he has participated in the radio program called "Torre de Babel" as part of this group.

Luis Alejandro Novoa Romero is a tenth semester student from the Modern language undergraduate program at UPTC. He is part of the research group TONGUE that belongs to the Modern Languages School, and he has participated in the radio program called "Torre de Babel" as part of this group.

Santiago Andrés Sandoval Suelta is a tenth semester student from the Modern language undergraduate program at UPTC. He is part of the research group TONGUE that belongs to the Modern Languages School, and he has participated in the radio program called "Torre de Babel" as part of this group.

\section{References}

Aguirre J., \& Ramos, B. (2014). Materials development in the Colombian context: Some considerations about its benefits and challenges. $H O W, A$ Colombian Journal for Teachers of English, 21(2), 134-150.

Andrade, M. (2014). Role of technology in supporting English language learners in today's

classrooms. (Master's thesis). University of Toronto.

Bedoya, P. (2014). The exercise of learner autonomy in a virtual EFL course in Colombia. HOW, A Colombian Journal for Teachers of English, 21(1), 82-102. 
Bolívar, M. (2013). ICT in the EFL

teaching in the public schools of the

department of Boyacá: An

overview to the world. Enletawa

Journal, 4, 127-136.

Blurton, C. (2002). New directions of ICT-

use in education. Retrieved from

http://www.unesco.org/education/e

ducprog/lwf/dl/edict.pdf;accessed.

Cariaga, R. (2016). Developing digital L2

literacy during compulsory schooling. ENLETAWA Journal, $8(2), 87-101$.

Castellanos, A. (2009). Fostering

communication through blogs in an international, multi-grade

context. HOW, A Colombian

Journal for Teachers of English, 16,
Clavijo, A., Hine, N. A., \& Quintero, L. M. (2008). The virtual forum as an alternative way to enhance foreign language learning. PROFILE: Issues in Teachers' Professional Development, 9(1), 219-235.

Cubides, N., \& Rodríguez, L. (2013).

Developing intercultural dimensions through the design of curricular units based on the Ganag Model. Enletawa Journal, 6, 21-36.

Cuesta, L. (2010). The design and development of online course materials: Some features and recommendations. PROFILE: Issues in Teachers' Professional Development, 12(1), 181-201.

Giraldo, F. (2013) The impact of a professional development program on English language 
teachers' classroom performance.

PROFILE: Issues in Teachers'

Professional Development, 16, 63-

76.

Houcine, S. (2011). The effects of ICT on learning/teaching in a foreign language.

Retrieved from http://www.pixelonline.net/ICT4LL2011/.../IBL69-

43

Kumaravadivelu, B. (2001). Toward a post method pedagogy. TESOL Quarterly, 35(4), 537-560.

La Verde, J. (2013). The relationship between videogames and English language learning. ENLETAWA Journal, 6, 131-132.

Muñoz, H. (2016). Mediaciones tecnológicas: Nuevos escenarios de la práctica pedagógica. Praxis \& Saber Revista de Investigación y Pedagogía, 13(7), 199-221.
Morales, Y. A. (2016). Unveiling

preservice teachers' attitudes toward teaching: The role of pedagogical practicums. PROFILE: Issues in Teachers Professional Development. 18(2), 47-61.

Pinzón, S., \& Guerrero, C. (2018). Living the teaching practicum within dichotomies: The story from within when implementing ICTs in the English language classroom $\mathrm{HOW}$, A Colombian Journal for Teachers of English, 25(2), 69-89.

Reinders, H. (2018). From dealing with teacher resistance to working on teacher resilience. ENLETAWA Journal, 11(1), 69-76.

Rogers, A. (2008). Using technology to facilitate process writing and interaction among adult students. PROFILE: Issues in Teachers' 
Professional Development, 9(1), 197-218.

Rojas, J. (2007). Technology applied to

ELT: Reviewing practical uses to enhance English teaching programs. HOW, A Colombian Journal for Teachers of English, 14, 143-159.

Salinas, Y. (2011). Project work

implementation in a virtual

Colombian public university environment. HOW, A Colombian Journal for Teachers of English, 18, 135-153.

Salinas, Y. (2014). Collaborative project work development in a virtual environment with low-intermediate undergraduate Colombian students. PROFILE Issues in Teachers' Professional Development, 16(1), $29-48$.
Tondeur, J., Hermans, R., Van Braak, J., \& Valcke, M. (2008). Exploring the link between teachers' educational beliefs profiles and different types of computer use in the classroom. Computers in Human Behavior, 24(6), 2541-2553. 